\title{
Pregnancy Rate of Bunaji Cows in a Fixed Time Al Synchronization Protocol Using Ovatide
}

Ubah Simon Azubuike ${ }^{1}$, Rekwot Peter Ibrahim ${ }^{2}$, Adewuyi Abdulmujeeb Bode ${ }^{2}$, Omontese Bobwealth Oakina ${ }^{2}$, Adeyeye Adewale Ayodeji ${ }^{3}$, Columbus Philemon Kwinjoh ${ }^{1}$, Abah Owoicho Kenneth ${ }^{1}$, Agbonu Oluwa Adikpe ${ }^{4}$ and Ejiofor Charles Ejike ${ }^{5}$

1. Department of Theriogenology, University of Abuja, Nigeria

2. Artificial Insemination Unit, National Animal Production Research Institute, Shika, Zaria, Kaduna State, Nigeria

3. Department of Theriogenology and Animal Production, Usmanu Danfodiyo University, Sokoto, Nigeria

4. Department of Veterinary Physiology and Biochemistry, University of Abuja, Nigeria

5. Department of Veterinary Parasitology, University of Abuja, Nigeria

\begin{abstract}
This study accessed the reproductive performance of Bunaji cows in an Ovsynch protocol involving ovatide. Bunaji cows $(n=16)$ aged 4-6 years and weighing between $250-350 \mathrm{~kg}$ with body condition scores (BCS) of 2.5-3.5 were used. There were two treatment groups for synchronization of ovulation. Treatment group 1 comprising Bunaji $(\mathrm{n}=8)$ received $50 \mu \mathrm{g}$ of gonadotropin releasing hormone $(\mathrm{GnRH})\left(\right.$ Cystorelin) and $25 \mathrm{mg}$ of $\mathrm{PGF}_{2 \alpha}$. While, treatment group 2 comprising Bunaji $(\mathrm{n}=8)$ received $50 \mu \mathrm{g}$ of ovatide and $25 \mathrm{mg}$ of $\mathrm{PGF}_{2 \alpha}$. All cows from both treatment groups were inseminated at $16 \mathrm{~h}$ after each second $\mathrm{GnRH}$ or ovatide injections. Cows that showed mucus discharge from the vagina on the day of artificial insemination (AI) were recorded as well as those that had patent cervix. Cervical dilation was measured by taking note of the cows that had mid cervix insemination due to non-passage of the AI gun through the cervix. Transrectal palpation was conducted twice at a month interval to select cycling cows within 5-12 d of the estrous cycle before initiating Ovsynch protocol. It was repeated on day 45 post AI to confirm pregnancies in animals. Results showed that the rate of mucus discharge from the vagina was $37.5 \%$ and $87.5 \%$ for ovatide and Cystorelin, respectively; while the rate of cervical dilation were $75 \%$ and $87.5 \%$ for ovatide and Cystorelin, respectively $(p>0.05)$, and pregnancy rates were $0 \%$ and $12.5 \%$ for ovatide and Cystorelin, respectively. There were no significant differences between the two groups. It was concluded that treatment of Bunaji cows with $50 \mu \mathrm{g}$ ovatide in Ovsynh protocol has heat and ovulation synchronization potentials and zero pregnancy rate. It was recommended that further studies be carried out using graded doses of 50, 100 and $150 \mu \mathrm{g}$ of ovatide in a fixed time AI synchronization protocol in Bunaji cows, to tap the potentials of the hormone in manipulation of bovine reproduction.
\end{abstract}

Key words: Pregnancy, ovatide, fixed time, AI, synchronization, cows.

\section{Introduction}

Major factors lowering reproductive performance in many dairy farms comprise difficulty in estrus detection in a timely and accurate manner, silent estrus and unknown time of ovulation [1,2]. Efficient and accurate estrus detection is essential in optimizing the economic management of individual cows to yield a profitable dairy operation. To maintain

Corresponding author: Ubah Simon Azubuike, Ph.D., research field: theriogenology. competitiveness, diary famers have increased average herd size and maximized milk production. These increases have been implicated as contributors to the lowered reproductive efficiency that is being experienced by many dairy farms. Reproductive performance appears to be directly related to herd management [3]. Calving intervals are increasing rather than decreasing, leading to a decrease in profits. Studies have indicated that the calving interval for optimal milk production and profit lies between 12-13 months [4-6]. Calving intervals longer than optimum 
occur when cows spend more time in the less profitable stage of lactation [4]. Several factors such as days to first artificial insemination (AI) service, including the voluntary waiting period (VWP), improper timing of $\mathrm{AI}$ and reduced conception rate at first AI are factors that prolong calving interval resulting in compromised profitability in dairy farming [6-11].

Increased rates of estrus detection would ideally increase pregnancy rates within set time limits, thereby leading to shorter calving intervals. Methods of estrus synchronization that optimize first service conception and reduce variability in days to first estrus may be useful in reducing the variability and duration of calving intervals for all cows in the herd [7]. Commercial gonadotropin releasing hormone $(\mathrm{GnRH})$ have been applied as new methods of synchronizing estrus (heat) in cows for AI. The synchronization allows farmers to inseminate cows with virtually no heat detection. This system was the first to avail producers the opportunity to have a dependable method with acceptable pregnancy rates to timed AI [12]. It has been reported that the GnRH systems out performed the older systems in cows nursing calves by increasing AI pregnancy rates to a single insemination. The most consistent systems were CO-Synch and Ovsynch. It was also documented that body condition of cows or semen handling were the major reasons for low pregnancy rates, in the CO-Synch and Ovsynch systems. In the olden estrus synchronization systems only heat, not ovulation was synchronized [12]. Looking at the two shot Lutalyse ${ }^{\circledR}$ system, the animals ovulate at various times over 5-7 d. GnRH system also has the advantage of reducing the length of the calving season [12]. The use of synthetic GnRH analogue to modify reproductive efficiency of normal dairy cows has been investigated widely [13]. In a study where $250 \mu \mathrm{g}$ of buserelin acetate (Receptal ${ }^{\circledR}$ ) was used on two occasions, i.e., once on day of estrus and second dose on days 10 or 12 or 14 , respectively, was reported to have registered a considerable higher conception rate of $83.33 \%$ each, while the control group cows had only $33.33 \%$ [14]. Literature stated that the number of services per conception was enhanced significantly for GnRH treated crossbred dairy cows. The days open and calving interval were reduced with statistical significance compared to the controls [15]. The use of GnRH analogue at the time of AI can enhance conception rate [16-18]. It was documented that the intravenous administration of $\mathrm{GnRH}$ at the time of AI improved the pregnancy rates of crossbred Bos indicus beef cows submitted to fixed time artificial insemination (FTAI) [17]. The use of GnRH injection $12 \mathrm{~d}$ post $\mathrm{AI}$, can improve pregnancy rate in repeat breeding cross bred dairy cows $[19,20]$. GnRH may be the choice of treatment for anestrous. In a trial, the use of GnRH analogue (buserelin acetate) therapy along with AI improved in pregnancy rate in repeat breeding cross breed cows. The scored conception rates were $68 \%$ and $59 \%$ in the first and the second treated groups, respectively, as compared to the control groups $(32 \%)(p<0.05)$ [19]. Many GnRH treatment regardless of days of administration resulted in an overall enhancement in conception rate of $83.33 \%$ as against $33.33 \%$ in control group of cows [14]. GnRH has been reported to favor conception rate if used during the luteal phase. Such increase in the conception rate has been ascribed to the fact that GnRH on day 5 stimulates ovulation of the first wave dominant follicle, after that ovulation a corpus luteum is formed which promotes progesterone production early in the cycle. This increase in progesterone secretion may facilitate embryonic development [2]. Parenteral administration of GnRH could initiate elevated endogenous progesterone level [21] through increased numbers and sizes of corporal lutea (CL) following luteal phase administration of GnRH [2]. This scenario leads to increase in total CL tissue area which is most likely to be responsible for the elevated serum concentration of progesterone observed under this condition.

$\mathrm{GnRH}$ administration at the time of $\mathrm{AI}$ improved 
conception rate in crossbred $(\mathrm{L} \times \mathrm{HF})$ dairy cows. It has been demonstrated that reducing the dose of GnRH to $50 \mu \mathrm{g}$ did not alter pregnancy rates. It was advised to use smaller gauge needles and smaller sizes of syringes to accurately administer the $50 \mu \mathrm{g}$ dose. This document also suggested that using the $100 \mu \mathrm{g}$ dose may compensate for injection errors [12].

Application of systematic breeding strategies that eliminate the need for estrus detection is necessary to optimize reproductive efficiency of dairy herds [22, 23]. Two effective systematic protocols included, ovulation synchronization (Ovsynch) protocol involving GnRH-PGF $2 \alpha^{-}$GnRH combination followed by timed-AI [24-26] and Targeted Breeding ${ }^{\mathrm{TM}}$ (Pharmacia Upjohn, Kalamazoo, MI) involving a series of $\mathrm{PGF}_{2 \alpha}$ administrations followed by $\mathrm{AI}$ at detected estrus. These systems facilitate the AI of more cows and increase the number of AI within a given period. Primary benefits of systematic breeding programs include the day-to-day convenience in managing the herd and the efficient use of labor for estrus detection and AI. In Ovsynch protocol, an injection of GnRH agonist is followed $7 \mathrm{~d}$ with an injection of $\mathrm{PGF}_{2 \alpha}$ and a second GnRH agonist $48 \mathrm{~h}$ after $\mathrm{PGF}_{2 \alpha}$ administration $\mathrm{AI}$ is then followed 12-18 $\mathrm{h}$ after second GnRH. GnRH will luteinize or ovulate the mature follicle and initiate recruitment and selection of a new dominant follicle $7 \mathrm{~d}$ later $[27,28]$. The administration of $\mathrm{PGF}_{2 \alpha}$ initiates regression of the spontaneous corpus luteum, or a potential corpus luteum induced by GnRH, or both. The second GnRH will induce a surge of luteinizing hormone $(\mathrm{LH})$, causing ovulation of the newly recruited, 9-day-old dominant follicle within $30 \mathrm{~h}$ of administration [29-31].

These protocols involve the use of expensive imported hormones in Nigeria. The use of ovatide which is a gonadotropin of fish origin may open the window for the use of pituitary extract of African catfish in synchronization protocol. This work was designed to access the reproductive performance of
Bunaji cows in an Ovsynch protocol involving ovatide with the objectives to determine rate of mucus discharge, cervical dilation and pregnancy rates of Bunaji cows in an Ovsynch protocol using GnRH and ovatide independently.

\section{Materials and Methods}

\subsection{Study Location}

This study was carried out at the cattle farm of Diary Research Programme (DRP) of the National Animal Production Research Institute (NAPRI), Shika, Ahmadu Bello University, Zaria. Shika is situated in the Northern Guinea Savannah between latitudes $11^{\circ}$ and $12^{\circ}$ and longitudes $7^{\circ}$ and $8^{\circ} \mathrm{E}$ at elevation of 659 $\mathrm{m}$ above sea level with an average annual maximum and minimum temperature of $31.0 \pm 3.2{ }^{\circ} \mathrm{C}$ and $18.0 \pm$ $3.7^{\circ} \mathrm{C}$, respectively. It has two distinct seasons: dry season (November to April) with mean daily temperature ranging from $15{ }^{\circ} \mathrm{C}$ to $36{ }^{\circ} \mathrm{C}$ and rainy season (May to October) with average annual rainfall of $1,100 \mathrm{~mm}$ and mean relative humidity of $72 \%$ [32].

\subsection{Research Animals and Management}

Bunaji cows $(n=16)$ aged 4-6 years and weighing between 250-350 kg were used. Selected cows with average body condition scores (BCS) of 2.5-3.5 using 0-5 scale from the most emaciated to the fattest [33]. Cows were identified by means of plastic ear tags. They were managed according to the routine management practice of the DRP. Two rectal examinations a month apart were carried out to ensure cyclicity of the cows before commencement of the study. Only cycling cows at $75 \mathrm{~d}$ post partum with palpable CL were included in the study.

\subsection{Experimental Design}

Cows were randomly assigned to one or two treatment groups for synchronization of ovulation. Treatment group 1 comprising Bunaji $(n=8)$ received $50 \mu \mathrm{g}$ of GnRH (Cystorellin; Nerial, Ltd., Iselin, NJ) and $25 \mu$ g of PGF $_{2 \alpha}$ (Lutalyse the Pharmacia-Upjohn 
Co., Kalamazoo, MI) (Fig. 1); while treatment group 2 comprising Bunaji $(\mathrm{n}=8)$ received $50 \mu \mathrm{g}$ of ovatide (Hemo Pharm. PVT Ltd., Mahalaxmi, Mumbai) and $25 \mathrm{mg}$ of $\mathrm{PGF}_{2 \alpha}$ (Fig. 2). All cows from both treatment groups were inseminated at $16 \mathrm{~h}$ after each second GnRH or ovatide injections as illustrated bellow.

\subsubsection{Treatment Group 1}

Bunaji cows administered first injection of $50 \mu \mathrm{g}$ of GnRH on the day 0 , followed by $25 \mathrm{mg}$ of $\mathrm{PGF}_{2 \alpha} 7 \mathrm{~d}$ later and a second injection of $50 \mu \mathrm{g} \mathrm{GnRH} 48 \mathrm{~h}$ after $\mathrm{PGF}_{2 \alpha}$ administration. Trans-rectal ultrasound was done $48 \mathrm{~h}$ from the last GnRH injection to detect corpus luteum and confirm ovulation [34].

\subsubsection{Treatment Group 2}

These cows were administered first injection of $50 \mu \mathrm{g}$ ovatide on day 0 , followed by $25 \mathrm{mg}$ of $\mathrm{PGF}_{2 \alpha} 7 \mathrm{~d}$ later and a second injection of $50 \mu \mathrm{g}$ ovatide $48 \mathrm{~h}$ after $\mathrm{PGF}_{2 \alpha}$ administration. Trans-rectal ultrasound was done $48 \mathrm{~h}$ from the last ovatide injection to detect corpus luteum and confirm ovulation.

Cows that showed mucus discharge from the vagina on the day of AI were recorded as well as those that had patent cervix (Figs. 3 and 4). Cervical dilation was measured by taking note of the cows that had mid cervix insemination due to non-passage of the AI gun through the cervix (Figs. 3-5). This applied to the two groups.

AI was achieved by thawing a straw of frozen semen in a thawing flask at $38{ }^{\circ} \mathrm{C}$ for $30 \mathrm{~s}$, subsequently the bovine AI gun universal was adequately loaded with the semen straw placed at an angle of $45^{\circ}$ upwards to avoid backflow of semen. Immediately after loading the warm gun shaft with the disposable sheath was passed through the vagina with the aid of the left hand in the rectum. Passage through the cervix was noted and the tip of the gun felt in the internal cervical os with the left index finger. Semen was deposited at the cervix or body of the uterus by pushing the plunger or piston forward. The gun was gently withdrawn after deposition of the semen (Fig. 5).

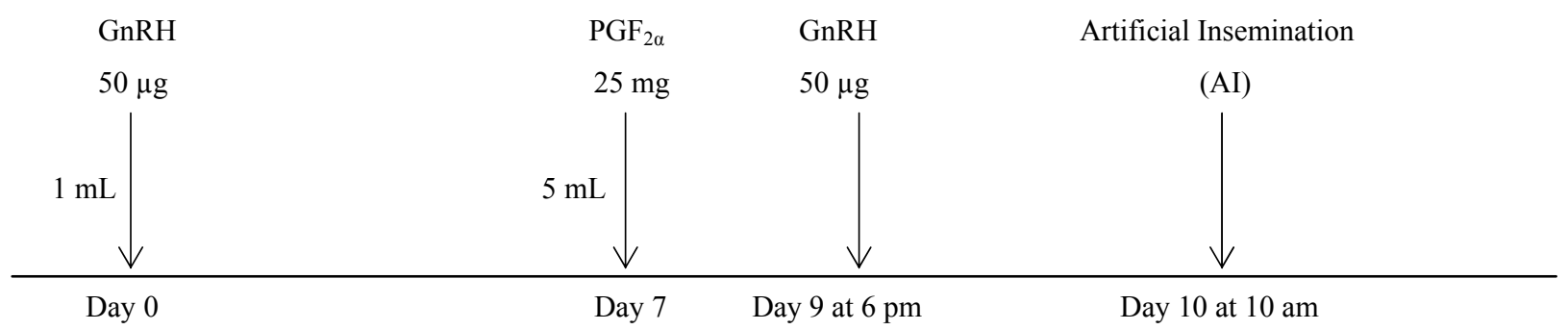

Fig. 1 Treatment schedule for group 1 involving gonadotropin releasing hormone (GnRH) and PGF . $_{2 \alpha}$

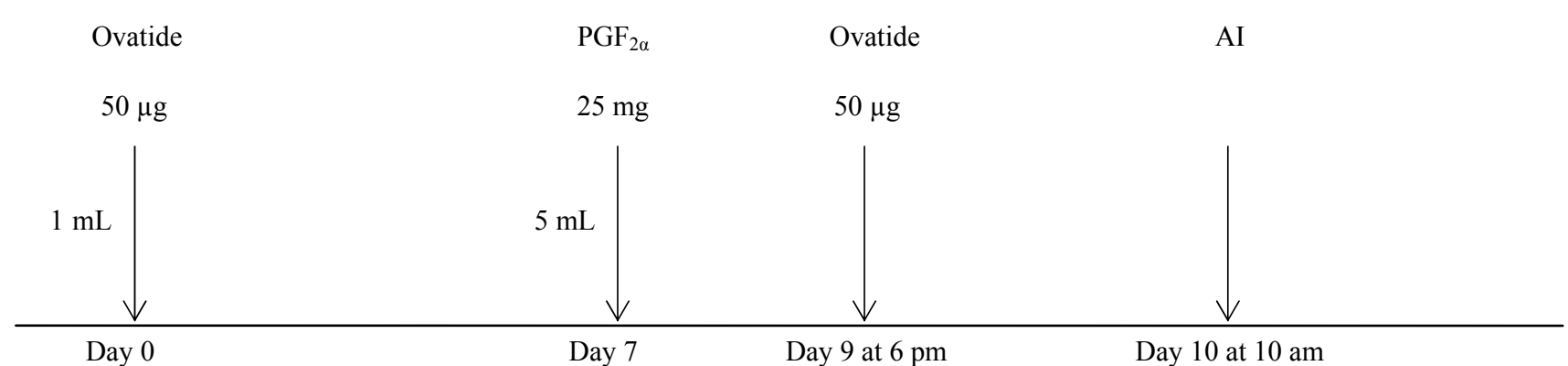

Fig. 2 Treatment schedule for group 2 involving ovatide and PGF $_{2 \alpha}$. 


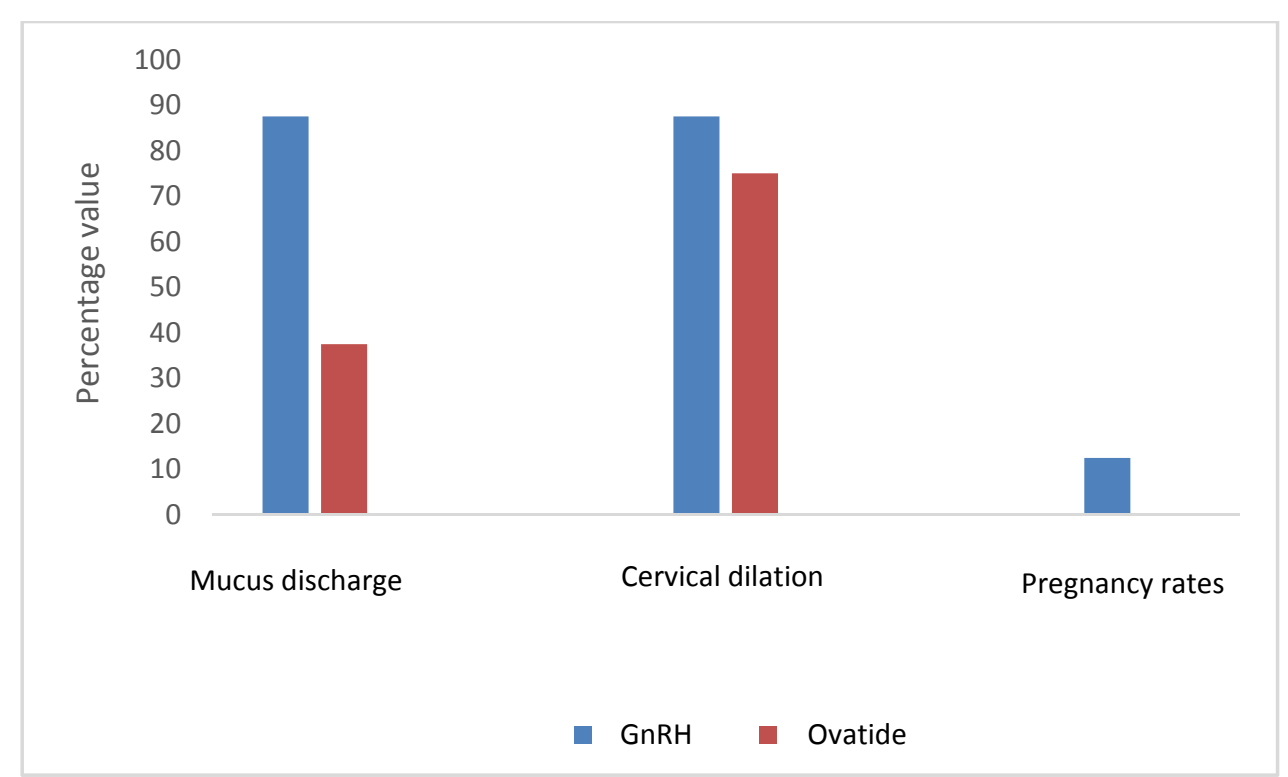

Fig. 3 Rate of mucus discharge, cervical dilation and pregnancy rates of ovatide and GnRH (Cystorellin) following the Ovsynch protocol and AI.

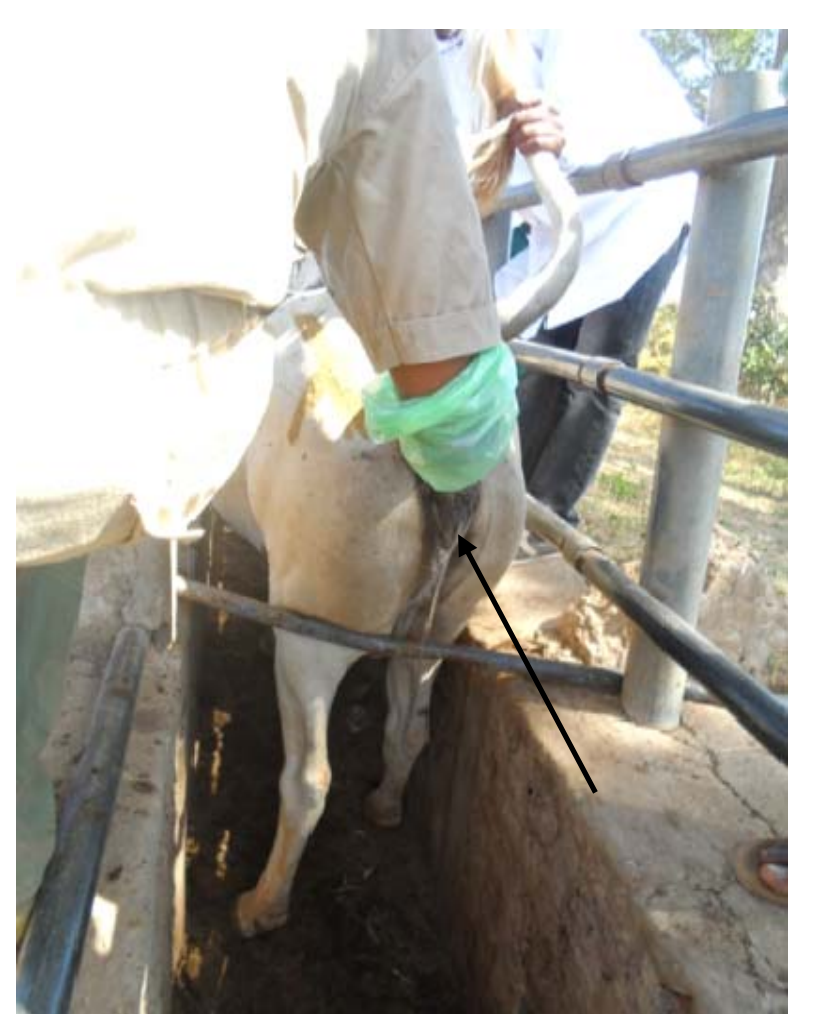

Fig. 4 Mucus discharge from the vagina on the day of AI.

The external genitalia was washed with water before starting the procedure. All hygienic measures were adopted to avoid possibility of infection at the time of AI.
Trans-rectal palpation was conducted twice at a month interval to select cycling cows within 5-12 d of the estrous cycle before initiating Ovsynch protocol. It was repeated on day 45 post AI to confirm pregnancies 


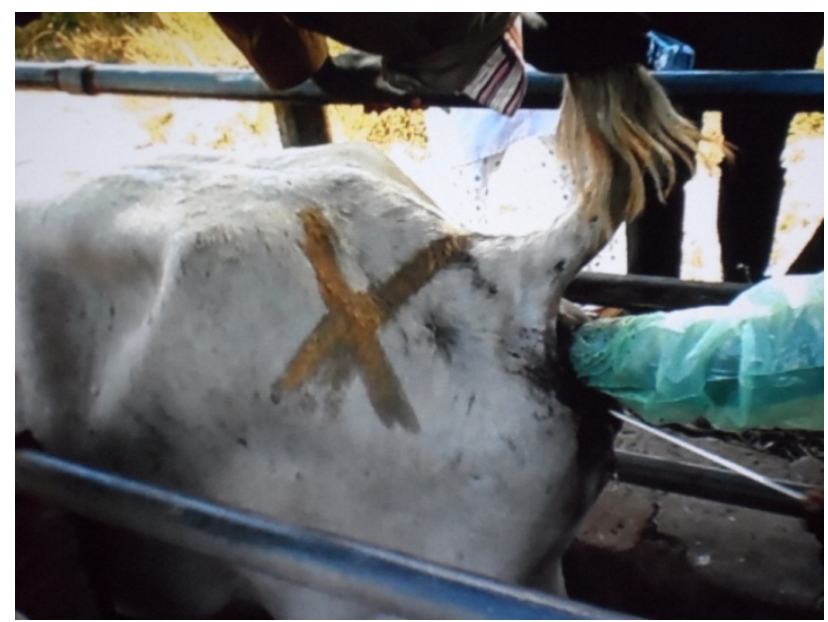

Fig. 5 AI on day 10, $16 \mathrm{~h}$ from the second GnRH/ovatide injection.

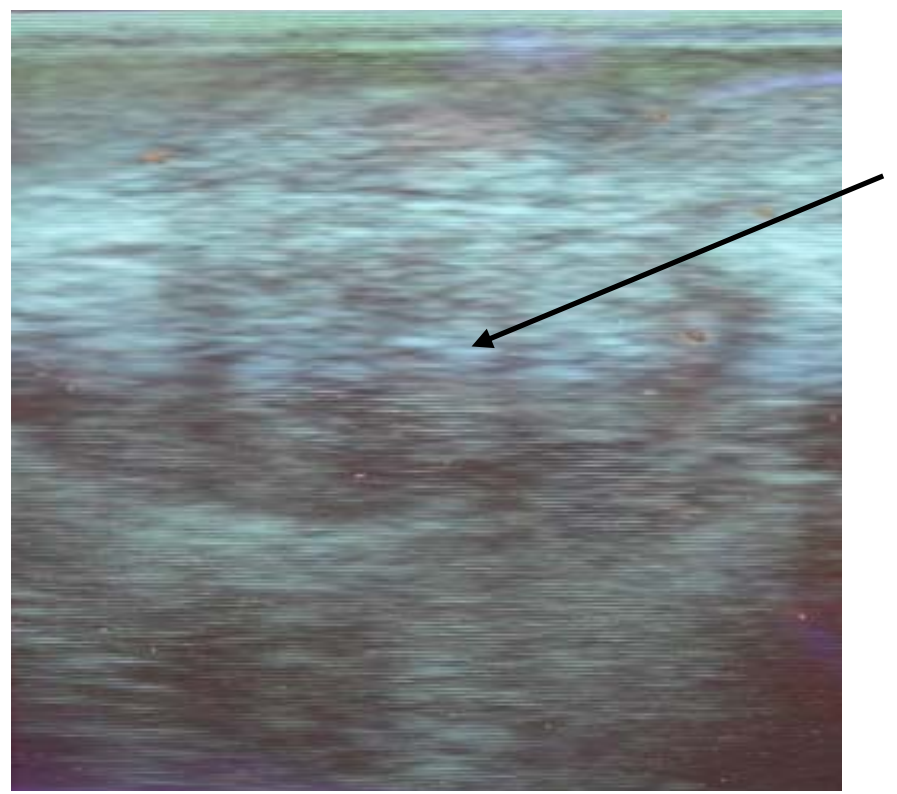

Fig. 6 Ultrasound evidence of corpus luteum/ovulation $48 \mathrm{~h}$ after the second GnRH/ovatide injection.

in animals. The third trans-rectal palpation aimed to detect presence of amniotic vesicle, fetal membrane slip and fetus as positives signs of pregnancy [35].

\subsection{Fertility Rates}

Pregnancy rate at $45 \mathrm{~d}$ post AI was calculated as the number of cows that were diagnosed pregnant at $45 \mathrm{~d}$ post AI expressed as a percentage of cows that received the Ovsynch protocol.

\subsection{Statistical Analysis}

Data obtained on rate of mucus discharge, rate of cervical dilation and pregnancy rate at $45 \mathrm{~d}$ post $\mathrm{AI}$ were expressed in percentages and represented in charts. Differences in the parameters between treatment groups were analyzed using chi-squares test. Values of $p<$ 0.05 were considered significant. Data analyses were carried out using Statistical Package for Social Sciences (SPSS) Version 17.0.0 (SPSS Inc. Chicago Il, USA).

\section{Results}

\subsection{Rates of Mucus Discharge and Cervical Dilation}

Mucus discharge from the vagina was a physical evidence of heat that was observed in some of the 
treated animals and the difference in the number of animals that showed mucus discharge was not significantly different between both groups (Fig. 3). Cervical dilation was noted during the passage of AI gun on the day of AI, the number of animals that allowed passage of the gun through the cervix and had intrauterine insemination were not significantly different between the two groups (Fig. 3).

The rate of mucus discharge for ovatide was $37.5 \%$ while that of GnRH was $87.5 \%, p=0.1189$, O.R $=$ 0.0857 ; the rate of cervical dilation for ovatide was $75 \%$ while that of $\mathrm{GnRH}$ was $87.5 \%, p=1.00, \mathrm{O} . \mathrm{R}=$ $1.80(\mathrm{O} . \mathrm{R}=$ odds ratio). There were no significant differences between the two groups.

\subsection{Pregnancy Rates}

Pregnancy rate is the no. of cows that were diagnosed pregnant $45 \mathrm{~d}$ post AI divided by the no. of cows that received Ovsynch protocol. Pregnancy rate for ovatide was $0 \%$ whereas $\mathrm{GnRH}$ had pregnancy rate of $12.5 \%$.

\section{Discussion}

Results indicated that mucus discharge and cervical dilation for Cystorelin and ovatide treatment groups were similar in heat synchronization potentials as well as ovulation synchronization in cows (Fig. 6). Although, Cystorelin at $50 \mu \mathrm{g}$ seems to be superior in synchronization efficiency in the cow compared to ovatide at $50 \mu \mathrm{g}$ (Fig. 3). A pregnancy rate of $0 \%$ was recorded for the ovatide at $45 \mathrm{~d}$ post AI while the GnRH (Cystorelin) had a pregnancy rate of $12.5 \%$. Generally fixed time AI programs have variable pregnancy rates depending on the particular protocol. It has been reported that the Ovsynch protocol alone is not as good as the Presynch + Ovsynch. Nearly all published information has shown that Presynch + Ovsynch produced better AI conception rates than using Ovsynch alone. This has been true when either 11, 12 or $14 \mathrm{~d}$ elapsed between the second Presynch injection and the onset of Ovsynch. The gain is about
10-15 percentage points [36]. Presynchronization is one of the strategies that have been employed to improve pregnancy rate of cows in fixed time AI programs. Pregnancy rates per AI at $29 \mathrm{~d}(59 \%$ versus $36 \%)$ and $57 \mathrm{~d}(45 \%$ versus $20 \%)$ after timed artificial insemination (TAI) were greater in cows treated with Ovsynch plus a progestin device (PD) than in those treated with Ovsynch alone. Fertility was particularly enhanced in acyclic animals (pregnancy rate of $64 \%$ versus 27\%) [37]. A comparable percentage of animals ( $89 \%$ and $95 \%)$ with plasma progesterone $>1$ $\mathrm{ng} / \mathrm{mL} 14 \mathrm{~d}$ after TAI suggests that both TAI protocols resulted in a similar response and induction of cyclicity. However, pregnancy rate was greater in cows subjected to Ovsynch plus PD protocol $(31 \%$ versus $23 \%$ ). The emergence of a new follicular wave is synchronized only when GnRH treatment causes ovulation [38]. If the first GnRH does not synchronize follicular wave emergence, ovulation following the second GnRH may be poorly synchronized [38], resulting in disappointing pregnancy rates following TAI [39]. The poor pregnancy rate observed in this study with the Cystorelin may be related to the number of animals in the study-only eight cows were tested in each group. Although, the present result is not completely far from other reports of pregnancy rate in the Ovsynch protocol, example pregnancy rates per AI at $29 \mathrm{~d}(59 \%$ versus $36 \%)$ and $57 \mathrm{~d}(45 \%$ versus $20 \%$ ) after TAI were greater in cows treated with Ovsynch plus a PD than in those treated with Ovsynch alone, means that the time of pregnancy diagnosis is also critical. A $20 \%$ pregnancy rate in Ovsynch protocol alone was close to the observed result of $12.5 \%$ at $45 \mathrm{~d}$ post AI.

The disappointing pregnancy rate observed with ovatide may be attributed to factors such as poor compliance and dose.

Anytime you add another cow handling to a program, you are likely raising the probability that not every cow will be treated with the right product at the right time. 
Just consider the Ovsynch program where cows are handled four times. If the probability of correctly treating a cow (finding and injecting her with the appropriate product on the correct day) is $95 \%$, then the probability that all cows are handled correctly at each of four handlings is only $81.4 \%(0.95 \times 0.95 \times$ $0.95 \times 0.95)$. In other words, compliance was $81 \%$. Poor compliance reduces timed AI conception rates. If cows were handled seven times as with the Double Ovsynch program with the same accuracy, compliance would be $70 \%$ [36].

Consider all factors before making a change in your timed AI program. Keeping things simple and understandable for everyone involved in the breeding program is priority one. Knowing the difference between products to be used, using proper syringe and needle sizes (18 gauge, 1.5 inch), and following instructions are key to a high rate of compliance and good AI conception rates [36]. There is no recommended dose of ovatide for cows. It has been reported that the dose of ovatide used in fish affects fertility parameters in fish. A study was conducted to evaluate ovatide doses $(0.6,0.8$ and $1.0 \mathrm{~mL} / \mathrm{kg}$ body weight (BW) of female) on breeding performance of Clarias batrachus in the subtropical region of Hisar. The breeding performance was judged on the basis of the total weight of stripped eggs, net fecundity, fertilization, hatching and survival. To judge the egg quality, the percent fertilization, hatching and survival of fry were considered. The results indicated that the total weight of stripped eggs and spawning fecundity were the highest $(p<0.05)$ when females were injected $1 \mathrm{~mL}(25 \mu \mathrm{g})$ of ovatide per kilogram BW compared to those injected with other dose levels. The lowest stripping response was observed with injection of $0.6 \mathrm{~mL}(15 \mu \mathrm{g})$ ovatide per kilogram BW of female brood fish. At the $1 \mathrm{~mL}$ dose, the percentages of total fertilized egg and hatching were $82.33 \%$ and $55.35 \%$, respectively, which were the highest $(p<0.05)$ among all treatments. The net survival of fry was found to be $98.52 \%$ at $1 \mathrm{~mL}$ ovatide per kilogram BW. Therefore, it has been recommended that $1 \mathrm{~mL}$ of ovatide per kilogram BW of female brood fish was found optimum among the three experimental doses for best breeding performance and egg quality in C. batrachus [40]. This report means that there is an optimum dose of ovatide that is required for ovulation to occur as reflected in the total number of stripped eggs in fish, it also means that fertilization requires an optimum dose. Therefore, standardizing the dose of ovatide in cows that would cause ovulation at the first gonadotropin injection, initiate new follicular wave emergence and give high fertilization and pregnancy rate at fixed time AI needs to be developed.

\section{Conclusions}

Mucus discharges and cervical dilations were observed in both groups $16 \mathrm{~h}$ after the second gonadotropin injection which did not differ significantly. A pregnancy rate of $0 \%$ and $12.5 \%$ was also recorded for ovatide and GnRH (Cystorelin), respectively. Treatment of Bunaji cows with $50 \mu \mathrm{g}$ ovatide in Ovsynch protocol has heat induction potentials considering the rate of mucus discharge and cervical dilation. Based on the outcome of this study, it was recommended that further studies be carried out using graded doses of 50, 100 and $150 \mu \mathrm{g}$ of ovatide in fixed time AI synchronization protocol in Bunaji cows. The use of a presynchronization treatment is also recommended to enhance pregnancy rates.

\section{References}

[1] Zakari, A. Y. 1981. "Manifestation and Detection of Oestrus in Bunaji and Bkoloji Cows." Ph.D. thesis, Ahmadu Bello University, Zaria, Nigeria.

[2] Sm, A. H., and Kamruzzaman, S. M. 2017. "Effects of GnRH on Conception Rate at the Time of Artificial Insemination in Crossbred Dairy Cows." International Journal of Animal Science and Technology 1 (1): 19-34. doi: 10.11648/j.ijast.20170101.14.

[3] Britt, J. H. 1985. "Enhanced Reproduction and Its Economic Implications." Journal of Diary Science 68: 1585-92.

[4] Call, E. P. 1978. "Economics Associated with Calving 
Intervals." In Large Diary Herd Management, edited by Wilcox, C. J., and Van Horn, H. H. Univ. Presses Florida, Gainesville, 90-201.

[5] Allalout, S. 1979. "The Effect of Calving Interval, Days Open, Previous Days Dry and Percentage Cow Days in Milk on Annual Yield per Cow." MSc. thesis, Washington State University.

[6] Lucy, M. C., Stevenson, J. S., and Call, E. P. 1986. "Controlling First Service and Calving Interval by Prostaglandin $\mathrm{F}_{2 \alpha}$ Gonadotropin-Releasing Hormone and Timed Insemination." Journal of Dairy Science 69: 2186-94.

[7] Pelissier, C. L. 1972. "Herd Breeding Problems and Their Consequences." Journal of Dairy Science 55: 385-91.

[8] Rollinson, D. H. L. 1963. "Reproductive Habits and Fertility of Indigenous Cattle to Artificial Insemination in Uganda.” Journal of Agricultural Science 60 (2): 279-84.

[9] Foote, R. H. 1975. "Oestrus Detection and Oestrus Detection Aids.” Journal of Diary Science 58: 248-56.

[10] Senger, P. L. 1994. "Heifers' Oestrus Detection Problem: New Concepts, Technologies and Possibilities.” Journal of Dairy Science 77: 2745-53.

[11] Sturman, H., Oltenacu, E. A. B., and Foote, R. H. 2000. "Importance of Inseminating Only Cows in Estrus." Theriogenology 53: 1657-68.

[12] John, B., Hall, M., and Cline, D. C. 2009. GnRH Based Estrus Synchronization Systems for Beef Cows. Virginia Cooperative Extension Virginia, Virginia State University, Publications and Educational Resources, VCE Publications/400/400-013.

[13] Ehlers, K., Halvorson, L., and Glob, L. 2013. Gonadotropin Releasing Hormone and Gonadotropin Releasing Hormone Receptors. Global Library of Women's Medicine.

[14] Mahesh, S. D. 2010. "Evaluation of Pre and Post Artificial Insemination Effect of GnRH Hormone on Conception of Repeat Breeder Deoni Cows." Veterinary World 3: 209-11.

[15] Faisal, O. A. 2015. "Management of Postpartum Reproductive Performance with Administration of GnRH or $\mathrm{PGF}_{2 \alpha}$ in Cross Bred Dairy Cows." Journal of Agriculture and Veterinary Science 8: 45-9.

[16] Birhanu, H., Berihu, G., Solmon, R., Alemselam, B., and Gebrhiwot, T. 2015. "Effects of Gonadotropin Releasing Hormone Analogue in Enhancements of Pregnancy in Repeat Breeding Dairy Cows in and around Mekelle, Tigray, Ethiopia." Animal and Veterinary Sciences 3 (1): 12-7.

[17] Danilo, D., Darren, D. H., Vitor, R. G. M., Graham, C. L., Francisco, R. G., Bruno, W., Gustavo, N. T., Márcio, S. S., Romildo, R. W., Melina, A. F. B., and Luiz, E. K. 2014. "The Effects of Intramuscular or Intravenous Injections of
Gonadotropin Releasing Hormone at Fixed-Time Artificial Insemination on Pregnancy Rates of Bos Indicus Beef Cows.” Braz. Arch. Biol. Technol. 57 (3): 361-6.

[18] Luigj, T., Gani, M., Bejo, B., and Rexhep, B. 2014. "Role of GnRH on Ovulation during Summer's Months in Cows." Anglisticum Journal 3 (6): 1-62.

[19] Birhanu, H., Berihu, G., Solmon, R., Alemselam, B., and Gebrhiwot, T. 2015. "Effects of Gonadotropin Releasing Hormone Analogue in Enhancements of Pregnancy in Repeat Breeding Dairy Cows in and around Mekelle, Tigray, Ethiopia.” Animal and Veterinary Sciences 3 (1): $12-7$.

[20] Jaswal. 2013. "The Effect of Administration of Gonadotropin Releasing Hormone Analogue at Estrus or during Luteal Phase on Reproductive Performance of Dairy Cows Maintained under Sub-temperate Climate." Iranian Journal of Veterinary Research 14: 57-60.

[21] Mehni, S. B., Shabankareh, H. K., Kazemi-Bonchenari, M., and Eghbali, M. 2012. "The Comparison of Treating Holstein Dairy Cows with Progesterone, CIDR and GnRH after Insemination on Serum Progesterone and Pregnancy Rates." Reproduction of Domestic Animal 47: 131-4.

[22] Walker, D., Ritchie, H., Hawkins, D., and Gibson, C. 1994. "Getting the Cows Herd' Bred." Michigan State University Extension (MSU), Extension Beef Bulletins-2329Q01.

[23] Schmitt, E. J. P., Diaz, T. C., Drost, M., and Thatcher, W. W. 1996. "Use of a Gonadotropin-Releasing Hormone Agonist or Human Chorionic Gonadotropin for Timed Insemination in Cattle." Journal of Animal Science 74: 1084-91.

[24] Pursley, J. R., Mee, M. O., and Wilkbank, M. C. 1995. "Synchronization of Ovulation in Dairy Cows Using PGF $_{2 \alpha}$ and GnRH." Theriogenology 44: 915-23.

[25] Pursley, J. R., Kosorok, M. R., and Wilbank, M. C. 1997a. "Reproduction Management of Lactating Dairy Cows Using Synchronization of Ovulation." Journal of Dairy Science 80: 301-6.

[26] Pursley, J. R., Wilkbank, M. C., Stevenson, J. S., Ottobre, J. S., Garverick, H. A., and Anderson, L. L. $1997 \mathrm{~b}$. "Pregnancy Rates per Artificial Insemination for Cows and Heifers Inseminated at a Synchronized Ovulation or Synchronized Oestrus." Journal of Dairy Science 80: 295-300.

[27] Macmillan, K. L., and Thatcher, W. W. 1991. "Effect of an Agonist of Gonadotropin-Releasing Hormone on Ovarian Follicles in Cattle." Biology of Reproduction 45: 883-9.

[28] Wolfenson, D., Thatcher, W. W., Savio, J. D., Badinga, L., and Lucy, M. C. 1994. "The Effect of a GnRH Analogue on the Dynamics of Follicular Development 


\section{Protocol Using Ovatide}

and Synchronization of Estrus in Lactating Cyclic Dairy Cows." Theriogenology 42: 633-44.

[29] Roche, J. F. 1975. "Control of the Time of Ovulation in Heifers Treated with Progesterone and Gonadotrophin-Releasing Hormone." Journal of Reproduction and Fertility 43: 471.

[30] Pursley, J. R., Kosorock, M. R., and Wilbank, M. C. 1994. "Reproductive Management of Lactating Dairy Cows Using Synchronization of Ovulation." Journal of Animal Science 72 (I): 69 (abstract).

[31] Silcox, R. W., Powell, K. L., Pursely, J. R., and Wilbank, M. C. 1995. "Use of GnRH to Synchronize Ovulation in Holstein Cows and Heifers Treated with GnRH and Prostaglandin." Theriogenology 43: 325 (abstract).

[32] Rekwot, P. I., Oyedipe, E. G., Barje, P. P., and Rwuaan, J. S. 1998. "Factors Affecting the Reproduction Performance of Cattle in Nigeria." Nigeria Veterinary Journal 19: 66-77.

[33] Pullman, N. B. 1978. "Condition Scoring of White Fulani Cattle." Tropical Animal Health and Production 10: 118-20.

[34] Frickle, P. M., and Welle, M. L. 2003. "Resynchronization of Ovulation Using Ovsynch to Induce Second Timed Artificial Insemination Service in Lactating Dairy Cows.” Journal of Dairy Science 86 (1): 52 (abstract).
[35] Voh, A. A. Jr. 1997. "Fertility and Embryonic Mortality Rates of Zebu Cows Following Oestrus Synchronization and Artificial Insemination.” Ph.D. thesis, Ahmadu Bello University, Zaria.

[36] Jeff, S. 2016. "What is the Best Timed AI Program?" Reproduction, Hoard's Dairy man.

[37] Melendez, P., Gonzalez, G., Aguilar, E., Loera, O., Risco, C., and Archbald, L. F. 2006. "Comparison of Two Estrus-Synchronization Protocols and Timed Artificial Insemination in Dairy Cattle.” J. Dairy Sci. 89: 4567-72.

[38] Martínez, M. F., Kastelic, J. P., Adams, G. P., Cook, R. B., Olson, W. O., and Mapletoft, R. J. 2002a. "The Use of Progestins in Regimens for Fixed-Time Artificial Insemination in Beef Cattle." Theriogenology 57: 1049-59.

[39] Martinez, M. F., Kastelic, J. P., Adams, G. P., and Mapletoft, R. J. 2002b. "The Use of a Progesterone-Releasing Device (CIDR-B) or Melengestrol Acetate with GnRH, LH, or Estradiol Benzoate for Fixed-Time AI in Beef Heifers.” J. Anim. Sci. 80: 1746-51.

[40] Sharma, K., Yadava, N. K., and Jindal, M. 2010. "Effect of Different Doses of Ovatide on the Breeding Performance of Clarias batrachus (Linn.)." Livestock Research for Rural Development 22 (4). http://www.lrrd.org/lrrd22/4/shar22069.htm. 